\title{
Aqueous extract of garlic (Allium sativum) administration alleviates high salt diet-induced changes in the aorta of adult Wistar rats: a morphological and morphometric study
}

\author{
Olusola S. Saka ${ }^{1}$, A. Omobola Komolafe ${ }^{1}$, Oludare Ogunlade ${ }^{2}$, Ahmed A. Olayode ${ }^{1}$, Alice A. Akinjisola ${ }^{3}$ \\ ${ }^{1}$ Department of Anatomy and Cell Biology, Faculty of Basic Medical Sciences, Obafemi Awolowo University, Ile-Ife, Osun-State, Nigeria \\ ${ }^{2}$ Department of Physiological Sciences, Faculty of Basic Medical Sciences, Obafemi Awolowo University, Ile-Ife, Osun-State, Nigeria \\ ${ }^{3}$ Department of Human Anatomy, Faculty of Basic Medical Sciences, Ladoke Akintola University of Technology, Ogbomoso, Oyo-State, Nigeria
}

\begin{abstract}
Objectives: This study was designed to determine the morphometric and histological changes of the wall of the thoracic aorta in high salt-fed adult Wistar rats and the possible ameliorative effects of aqueous extract of garlic (Allium sativum).

Methods: Twenty-five healthy female Wistar rats weighing 130-180 $\mathrm{g}$ were randomly assigned into five groups of five rats each (Groups A, B, C, D and E). Rats in Group A were fed with standard laboratory pellets, while Groups B, C, D and E were fed on the high-salt diet for five weeks. Thereafter, daily administration of $50 \mathrm{mg} / \mathrm{kg}, 100 \mathrm{mg} / \mathrm{kg}$ and $150 \mathrm{mg} / \mathrm{kg}$ of the garlic extract were giving orally to Groups C, D and E, respectively for 3 weeks while rats in Groups A and B were administered distilled water. The thoracic part of descending aorta at the level of (T6-T7) was excised for histological studies. Paraffin sections were stained with haematoxylin and eosin, Masson's trichrome and Verhoeff-Van Gieson stains. One-way ANOVA was used to analyze data, followed by Student-Newman-Keuls (SNK) test for multiple comparisons.

Results: High salt diet causes significant histomorphological changes on aorta of rats as evidenced by increase in tunica intima, media and adventitia of the aortic wall and decrease in luminal diameter; these findings were reversed by aqueous garlic extract administration.
\end{abstract}

Conclusion: High salt diet increased the thickness of aortic wall and decreased luminal diameter which were significantly reversed by oral administration of garlic extract.

Keywords: aorta; garlic; heart; high salt-fed

Anatomy 2016;10(1):8-15 C2016 Turkish Society of Anatomy and Clinical Anatomy (TSACA)

\section{Introduction}

Garlic is reported to have prophylactic and therapeutic properties in conditions such as microbial infections, thrombosis, hypertension, hyperglycemia, hyperlipidemia, cancer, and thrombosis. ${ }^{[1,2]}$ The contents of garlic extract include sulfur active compounds mainly in the form of cysteine derivatives such as S-alkyl cysteine and sulfoxides, which are decomposed to thiosulfinates and polysulfides by allinase on extraction..$^{[3-5]}$
Aqueous extract of garlic (Allium sativum) prevents platelet aggregation and oxidative stress. ${ }^{[6,7]}$ The cardioprotective effects of garlic are related to its antiatherogenic properties, cholesterol lowering effect and improvement of vascular function. ${ }^{[7,8]}$

High salt intake leads to increased peripheral vascular resistance; a variety of factors appear to contribute to an augmented vascular reactivity to $\alpha$-adrenoceptor agonists reported in laboratory animals. ${ }^{[9,10]}$ Increased generation of reactive oxygen species and a down-regulation of nitric 
oxide synthase (NOS) subtypes are observed with high salt intake. ${ }^{[1,12]}$ In spontaneously hypertensive rats and Dahl salt-sensitive rats, high salt intake produced impaired endothelium dependent relaxation. ${ }^{[9,13,14]}$

A high salt intake also leads to changes in the renin-angiotensin system. The expression of angiotensin type 1 (AT1) receptors is altered in high salt diet in arteries of Dahl salt-sensitive or resistant rats and Wistar rats. ${ }^{[15-17]}$ This study investigated the effect of aqueous garlic extract as an alternative therapeutic method, studying the morphometric and histological changes of the wall of the thoracic aorta on high salt-fed adult Wistar rats.

\section{Materials and Methods}

\section{Animal care and management}

Twenty-five healthy female Wistar rats (130-180 g) from the Animal Holding of College of Health Sciences, Obafemi Awolowo University Ile-Ife were used for this study. The rats were randomly assigned into 5 groups of 5 rats each (Groups A, B, C, D and E). They were maintained on standard laboratory rat pellet before the commencement of the experiment and water was provided $a d$ libitum.

\section{Plant material and preparation of extract}

Cloves of garlic bulb were procured from Sabo market in Ile-Ife and identified by a taxonomist in the Department of Botany, Obafemi Awolowo University, Ile-Ife. They were weighed and then blended with water. Cloves were filtered into a conical flask using filter paper and a funnel to produce a clear juice. Then, the filtrate was freezedried using a lyophilizer and stored in a desiccator. An aliquot portion of the crude extract residue was dissolved in distilled water and administered on each day of the experiment. ${ }^{[18]}$

\section{Preparation of high salt diet}

High salt diet containing $8 \%$ sodium chloride was prepared specially by replacing $0.3 \%$ sodium chloride-containing standard diet with $8 \%$ sodium chloride. ${ }^{[1,20]}$

\section{Animal treatment}

Group A was the control, Group B was negative control, while Groups C, D and E were the test groups. Rats in Group A were fed with standard laboratory pellets, while Groups B, C, D and E were fed on the high-salt diet for five weeks. Thereafter, daily administration of $50 \mathrm{mg} / \mathrm{kg}$, $100 \mathrm{mg} / \mathrm{kg}$ and $150 \mathrm{mg} / \mathrm{kg}$ of the garlic extract were giving orally to Groups C, D and E, respectively for 3 weeks, while rats in Group B was left untreated for the same period. The extract solution was administered orally, using oral cannula, and the duration of the experiment was 8 weeks.

\section{Sacrifice of animals}

At the end of the experiment, the rats were sacrificed under ketamine anesthesia. The thoracic part of descending aorta at the level of T6-T7 were excised and weighed.

\section{Histological techniques}

The excised aorta was fixed in neutral buffered formalin for 24 hours, and processed using paraffin wax embedding method. Sections of $5 \mu \mathrm{m}$ thickness were cut from the paraffin embedded tissues and stained with haematoxylin and eosin stain to demonstrate the general histoarchitecture of the aorta. ${ }^{[2]}$ Masson's trichrome stain was used to demonstrate collagen fibers in the descending thoracic aorta, while Verhoeff-Van Gieson stain was used to demonstrate elastic fibers in the thoracic $\operatorname{aorta}^{[22,23]}$

\section{Photomicrography}

Stained sections were viewed under a Leica DM750 microscope (Leica Microsystems, Heerbrugg, Switzerland) with digital camera attached (Leica ICC50) and digital photomicrographs were taken at various magnifications. Photomicrographs of stained sections were imported onto the ImageJ version 1.48 (NIH, Bethesda, MD, USA) software for histomorphometric analysis of tunica intima, media and adventitia and lumen diameter.

\section{Quantification of staining intensity}

Image analysis and processing for Java (ImageJ), was used to analyze and quantify Masson's trichrome and VerhoeffVan Gieson staining intensity. Imported RGB images were converted to grayscale images on ImageJ. The software quantifies staining intensity by measuring the pixel value of each pixel in grayscale images following threshold of areas of staining activity and converting the pixel value to brightness value or gray value, in a scale of 0 to 255 from less brighter (that is more intensity) to more brighter (that is less intensity).

\section{Statistical analysis}

One-way ANOVA was used to analyze data, followed by Student-Newman-Keuls (SNK) test for multiple comparisons. GraphPad Prism 5 (Version 5.03; Graphpad Software Inc., San Diego, CA) was the statistical package used for data analysis. Statistically significant difference was set at $\mathrm{p}<0.05$. 


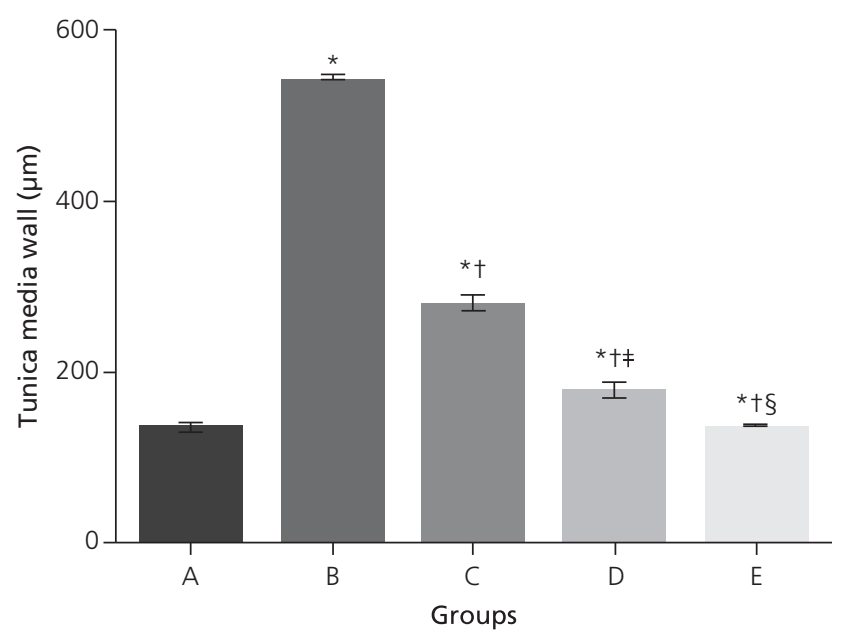

Figure 1. Effect of garlic on tunica media of aortic wall of rats fed with high salt diet $(n=5)$. Values are expressed as mean $\pm S E M$, * relative to control at $p<0.05$, †relative to Group B (high salt-fed) at $p<0.05$, $\neq$ relative to Group C (high salt diet $+50 \mathrm{mg} / \mathrm{kg}$ of garlic extract) at $p<0.05$, Srelative to Group D (high salt diet $+100 \mathrm{mg} / \mathrm{kg}$ of garlic extract) at $p<0.05$.

\section{Results}

There was a significant difference in thickness of the tunica media of the aortic wall across all experimental groups $\left(\mathrm{F}_{4,20}=530.8 ; \mathrm{p}<0.05\right)$. Post hoc analysis showed that thickness of the tunica media of the aortic wall of high salt-fed group was significantly increased compared to the control group $(\mathrm{p}<0.05)$. The thickness of the tunica media of the aortic wall which was increased by the high salt diet was significantly and dose dependently reversed by garlic extract administration (Figure 1). There was also a significant difference in thickness of

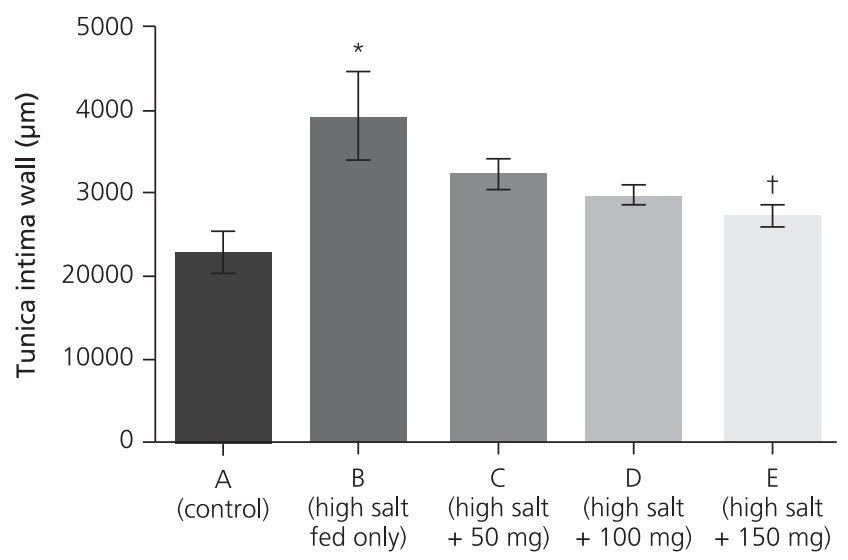

Figure 3. Effect of garlic on tunica intima of aortic wall of rats fed with high salt diet. $n=5$, values are expressed as thickness of tunica intima of aortic wall $(\mu \mathrm{m}) \pm S E M$, * relative to control at $p<0.05$, trelative to Group B at $p<0.05$.

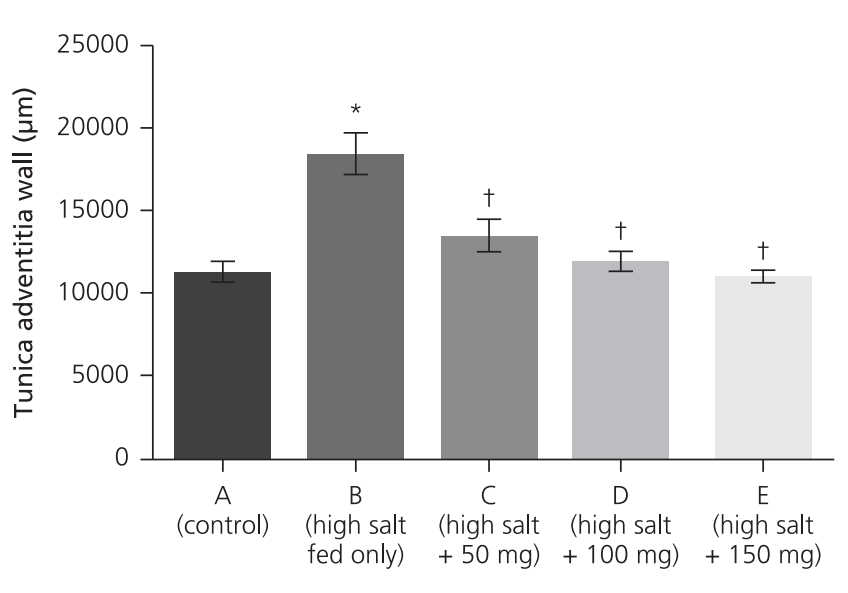

Figure 2. Effect of garlic on tunica adventitia of aortic wall of rats fed with high salt diet. $n=5$, values are expressed as mean $\pm S E M$, * relative to control at $p<0.05$, 'relative to Group B at $p<0.05$.

tunica adventitia of the aortic wall across all experimental groups $\left(\mathrm{F}_{4,20}=13.49 ; \mathrm{p}<0.05\right)$. Thickness of the tunica adventitia of aortic wall of high salt-fed group was significantly higher than the control group $(\mathrm{p}<0.05)$. The thickness of the tunica adventitia of aortic wall which was increased by the high salt diet was significantly and dose dependently reversed by garlic extract (Figure 2). Significant difference in thickness of the tunica intima of aortic wall was observed across all experimental groups $\left(\mathrm{F}_{4,20}=4.321 ; \mathrm{p}<0.05\right)$. Thickness in tunica intima of the aortic wall of high salt-fed group was significantly higher than the control group $(\mathrm{p}<0.05)$. This effect was sig-

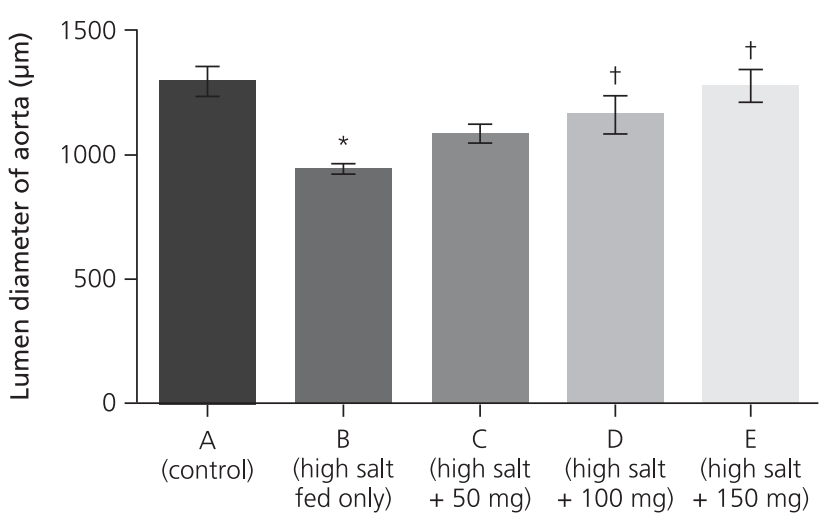

Figure 4. The lumen diameter of aorta of rats fed with high salt diet. $n=5$, values are expressed as mean $\pm S E M$ of data obtained, * relative to control at $p<0.05$, trelative to Group $B$ at $p<0.05$. 

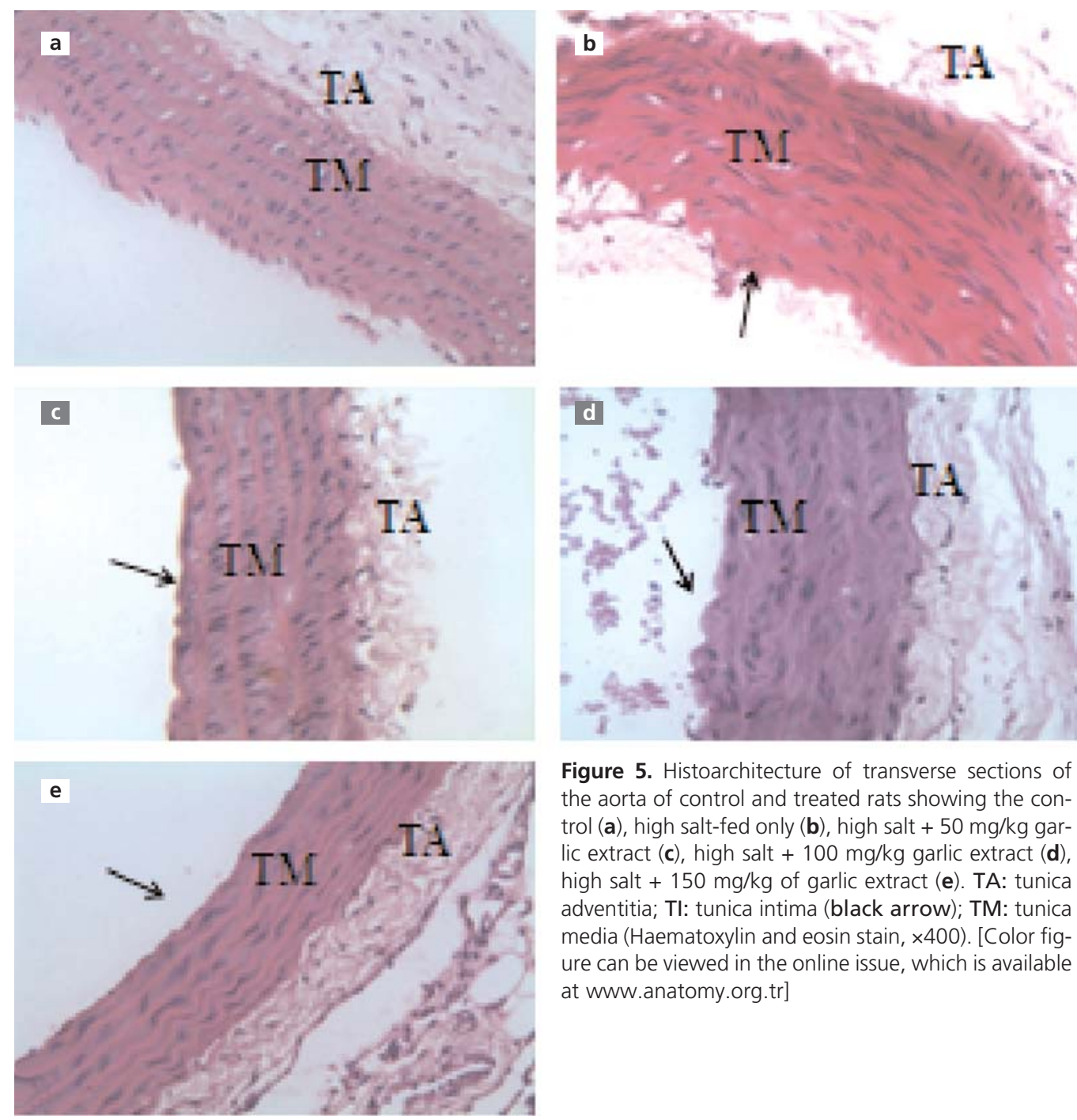

Figure 5. Histoarchitecture of transverse sections of the aorta of control and treated rats showing the control (a), high salt-fed only (b), high salt + $50 \mathrm{mg} / \mathrm{kg}$ garlic extract (c), high salt $+100 \mathrm{mg} / \mathrm{kg}$ garlic extract (d), high salt $+150 \mathrm{mg} / \mathrm{kg}$ of garlic extract (e). TA: tunica adventitia; TI: tunica intima (black arrow); TM: tunica media (Haematoxylin and eosin stain, $\times 400$ ). [Color figure can be viewed in the online issue, which is available at www.anatomy.org.tr]

nificantly and dose dependently reversed by garlic extract administration (Figure 3). The luminal diameter of aorta in Group B was significantly lower than the control group $(\mathrm{p}<0.05)$; this was also significantly and dose dependently reversed by aqueous garlic extract in Groups D and E (Figure 4).

Figure 5a shows the photomicrograph of the section of a descending aorta in the control group revealing the three basic layers of the blood vessel, the tunica intima, tunica media and the tunica adventitia. In the high saltfed group, tunica media was thicker compared to the control, but with fewer stained nuclei comparatively (Figure 5b). Figure 5c shows the thicker wall. Figures $\mathbf{5 d}$ and $\mathbf{5 e}$ show the three layers with similar architecture as control. There was an increase of collagen fibers in histological sections from aorta of the rats (Figures 6 and 7). The distribution of elastic fibers (black) in Figures $\mathbf{8 b}$ and $\mathbf{8 c}$ were reduced when compared with Figure 8a (control group). In Figures 8d and 8e, there was significant improvement in the deposition of elastic fibers. This was also observed in analysis of the area of elastic fibers (Figure 9).

\section{Discussion}

A morphometric and microanatomical study on the effects of aqueous garlic extract on aorta of high salt-fed adult Wistar rats was carried out in this study. It was observed that the tunica intima, media, adventitia and lumen diameter of the aorta were significantly higher in the high saltfed group than the control group $(\mathrm{p}<0.05)$. This suggests that high salt diet resulted in hypertrophy of the aortic walls which are in accordance with the earlier studies by 

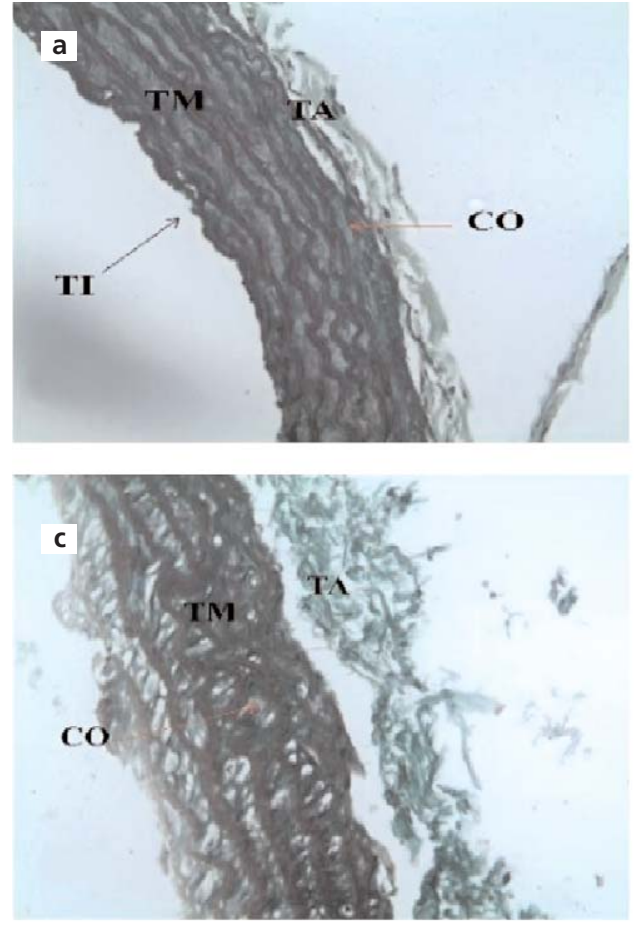

TI

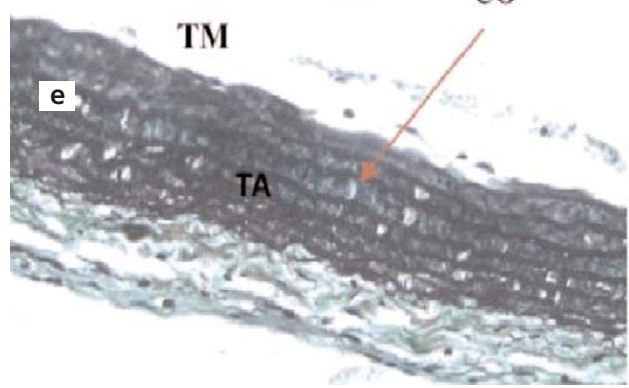

Ofem et al..$^{[24]}$ and Adewole et al. ${ }^{[25]}$ Increasing evidence from multiple clinical studies showed that excess salt intake was associated to cardiovascular damage, independent of blood pressure. ${ }^{[26]}$ The pathophysiological mechanisms responsible for high salt diet-induced changes remains debatable.

In this study, the hypertrophy of the aortic walls caused by high salt diet and also the sparse distribution of elastic fibers in Figure $\mathbf{8 b}$ was an evidence of injury in that group, as sparsely distributed of elastic fibers reduced the tensile strength and elasticity of the vascular structures which could lead to rupture of the arterial wall. ${ }^{[27]}$ This morphological change was significantly ameliorated by the garlic extract. ${ }^{[27]}$ The impairment of aortic elastic properties in the present research may be due to the direct effect of the high salt diet on the aorta of the rats. The increased stiffness of the aorta was asso-
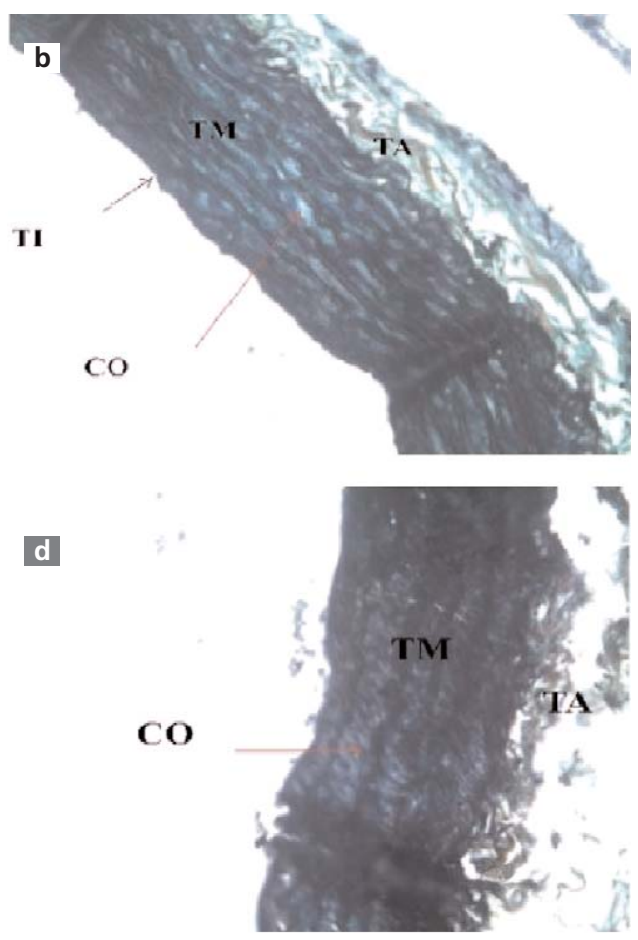

Figure 6. Collagen fibers in transverse sections of the aorta of control and treated rats showing control (a), high salt-fed only (b), high salt $+50 \mathrm{mg} / \mathrm{kg}$ garlic extract (c), high salt $+100 \mathrm{mg} / \mathrm{kg}$ garlic extract (d), high salt $+150 \mathrm{mg} / \mathrm{kg}$ of garlic extract (e). CO: collagen; TA: tunica adventitia, TI: tunica intima; TM: tunica media (Masson's trichrome stain $\times 400$ ). $n=5$, values are expressed as mean $\pm \mathrm{SEM}$, * relative to control at $p<0.05$. [Color figure can be viewed in the online issue, which is available at www.anatomy.org.tr]

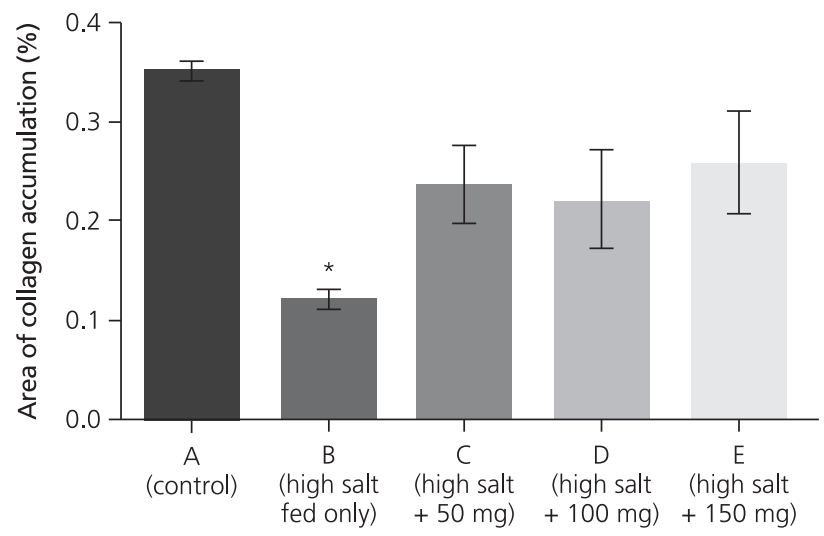

Figure 7. Collagen content measured by digital densitometry is shown as a result of collagen content in each specimen in percentage. Effect of garlic on area of collagen accumulation was determined by digital densitometry recognition and expressed as percentage of the total area of the field using Image J software. 

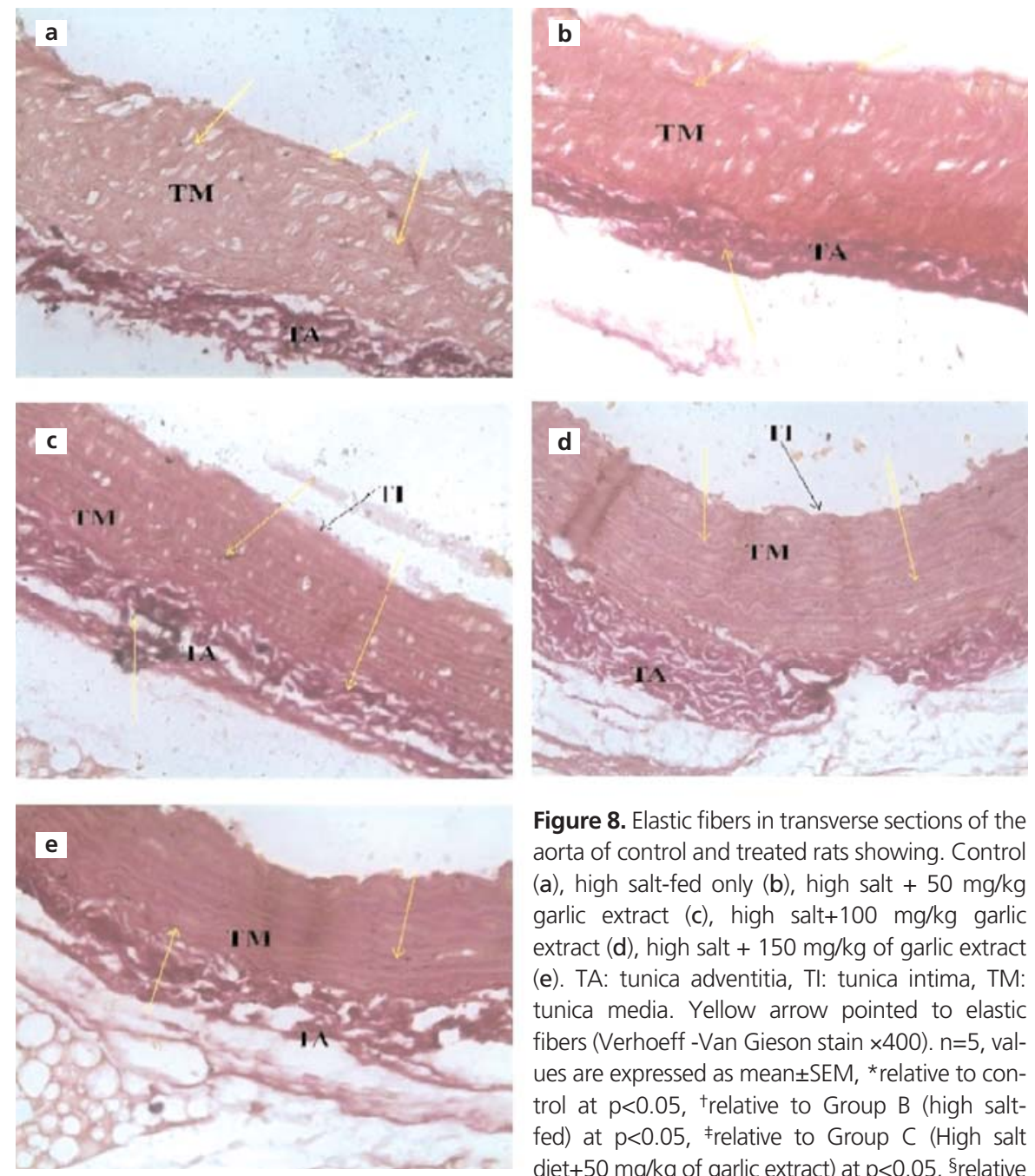

Figure 8. Elastic fibers in transverse sections of the aorta of control and treated rats showing. Control (a), high salt-fed only (b), high salt $+50 \mathrm{mg} / \mathrm{kg}$ garlic extract (c), high salt+100 mg/kg garlic extract (d), high salt $+150 \mathrm{mg} / \mathrm{kg}$ of garlic extract (e). TA: tunica adventitia, TI: tunica intima, TM: tunica media. Yellow arrow pointed to elastic fibers (Verhoeff -Van Gieson stain $\times 400$ ). $n=5$, values are expressed as mean \pm SEM, * relative to control at $p<0.05$, trelative to Group $B$ (high saltfed) at $p<0.05$, ₹relative to Group $C$ (High salt diet+50 $\mathrm{mg} / \mathrm{kg}$ of garlic extract) at $p<0.05$, Srelative to Group D (High salt diet+100 mg/kg of garlic extract) at $p<0.05$. [Color figure can be viewed in the online issue, which is available at mww.anatomy.org.tr]

ciated with the development of cardiovascular diseases. ${ }^{[28]}$ In addition, the increased thickness of the tunica media may be partly due to the increased medial smooth muscle cells observed in the high salt-fed group. The active ingredient in garlic extract is known as allicin (diallyl thiosulfinate) which is mainly an organosulfur that has been shown to inhibit renin-angiotensin-aldosterone system and prostaglandin synthesis. ${ }^{[29]}$ Garlic has been reported to exhibit potent angiotensin converting enzyme (ACE) inhibitory activity. ${ }^{[30]}$ The reduction in ACE activity results in reduction of plasma level of angiotensin II. Angiotensin II is also known to cause cardiovascular changes and sodium ion retention through stimulation of aldosterone release. ${ }^{[31,32]}$ Garlic extractinduced inhibition of ACE probably leads to reduction in angiotensin II, leading to decrease in adrenal production of aldosterone. ${ }^{[3]}$ The garlic extract-induced-reduc-

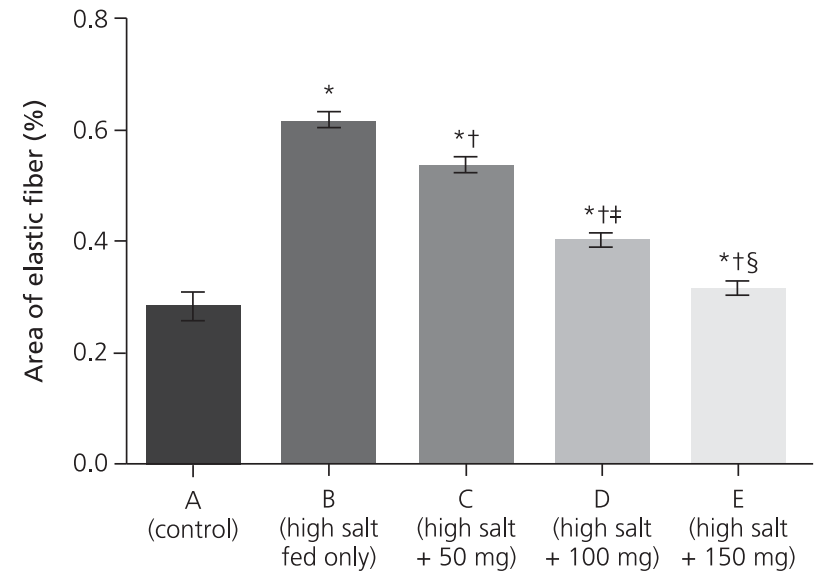

Figure 9. Elastic fiber content measured by digital densitometry is shown in each specimen in percentage. Effect of garlic on area of elastic fiber accumulation was determined by digital densitometry recognition and expressed as percentage of the total area of the field using Image I software. 
tion of plasma level of angiotensin II followed by natriand diuresis may be responsible for the reversal of the high salt-induced vascular and aortic wall hypertrophy reported with morphometric measurements in this study.

\section{Conclusion}

The results of this study indicated that high salt diet causes significant histomorphological changes on aorta of rats as evidenced by increase in tunica intima, media and adventitia of the aortic wall and decrease in luminal diameter; these findings were reversed by aqueous garlic extract administration. The restorative and ameliorative effects of garlic extract on high salt diet-induced changes in cardivascular system are probably via inhibition of renin-angiotensin-aldosterone system.

\section{References}

1. Ashraf R, Aamir K, Shaikh AR, Ahmed T. Effects of garlic on dyslipidemia in patients with type 2 diabetes mellitus. J Ayub Med Coll Abbottabad 2005;17:60-4.

2. Pittler MH, Ernst E. Clinical effectiveness of garlic (Allium sativum). Mol Nutr Food Res 2007;51:1382-5.

3. Augusti KT. Therapeutic value of onion (Allium cepa L.) and garlic (Allium sativum L.). Indian J Exp Biol 1996;34:634-40.

4. Kaye AD, De Witt BJ, Anwar M, Smith DE, Feng CJ, Kadowitz PJ, Nossaman BD. Analysis of responses of garlic derivatives in the pulmonary vascular bed of the rat. J Appl Physiol 2000;89:353-8.

5. Batirel HF, Naka Y, Kayano K, Okada K, Vural K, Pinsky DJ, Oz MC. Intravenous allicin improves pulmonary blood flow after ischemia-reperfusion injury in rats. J Cardiovasc Surg 2002;43: 175-9.

6. Zbinden S, Seiler Ch. Phytotherapy in cardiovascular medicine. Ther Umsch 2002;59:301-6.

7. Vazquez-Prieto MA, González RE, Renna NF, Galmarini CR, Miatello RM. Aqueous garlic extracts prevent oxidative stress and vascular remodeling in an experimental model of metabolic syndrome. J Agric Food Chem 2010;58:6630-5.

8. Melzig MF, Krause E, Franke S. Inhibition of adenosine deaminase activity of aortic endothelial cells by extracts of garlic (Allium sativum L.). Pharmazie 1995;50:359-61.

9. Nishida Y, Ding J, Zhou M, Chen Q, Murakami H, Wu X.Z, Kosaka H. Role of nitric oxide in vascular hyperresponsiveness to norepinephrine in hypertensive Dahl rats. J Hypertens 1998;16: 1611-8.

10. Sofola OA, Knill A, Hainsworth R, Drinkhill M. Change in endothelial function in mesenteric arteries of sprague-dawley rats fed a high salt diet. J Physiol 2002;543:255-60.

11. Lenda DM, Sauls BA, Boegehold MA. Reactive oxygen species may contribute to reduced endothelium dependent dilation in rats fed high salt. Am J Physiol Heart Circ Physiol 2000;279:H7-14.

12. Ni Z, Vaziri ND. Effect of salt loading on nitric oxide synthase expression in normotensive rats. Am J Hypertens 2001;14:155-63.
13. Kagota S, Tamashiro A, Yamaguchi Y, Sugiura R, Kuno T, Nakamura K, Kunitomo M. Downregulation of vascular soluble guanylate cyclase induced by high salt intake in spontaneously hypertensive rats. Br J Pharmacol 2001;134:737-44.

14. Luscher TF, Raij L, Vanhoutte PM. Endothelium-dependent vascular responses in normotensive and hypertensive Dahl rats. Hypertens 1987;9:157-63.

15. Wang DH, Du Y. Regulation of vascular type 1 angiotensin II receptor in hypertension and sodium loading: role of angiotensin II. J Hypertens 1998;16:467-75.

16. Strehlow K, Nickenig G, Roeling J, Wassmann S, Zolk O, Knorr A, Bohm M. AT(1) receptor regulation in salt-sensitive hypertension. J Physiol Heart Circ Physiol 1999;277:H1701-7.

17. Wang JM, Veerasingham SJ, Tan J, Leenen FH. Effects of high salt intake on brain AT1 receptor densities in Dahl rats. J Physiol Heart Circ Physiol 2003;285:H1949-55.

18. Jamshid Ghiasi G, Yahya E, Ramin Salamatdout N. Effect of garlic (Allium sativum) aqueous extract on serum values of urea, uricacid and creatinine compared with chromium chloride in male rats. Annals of Biological Research 2012;3:4485-90.

19. Obiefuna PC, Obiefuna IP. Salt-induced hypertension in rats alters the response of isolated aortic rings to cromakalim. West Indian Med J 2001;50:17-21.

20. Adigun SA, Akinyanjuola OB. Salt induced hypertension is maintained by autonomic nervous system and calcium but not by rennin angiotensin system, vasopressin and prostaglandin. Niger J Physiol Sci 1991;7:88-99.

21. Drury RA, Wallington EA. Carleton's histological technique. 5th ed. New York (NY): Oxford University Press; 1980. pp. 188-9, 237-40, 290- 1 .

22. Masson P. Some histological methods. Trichrome stainings and their preliminary technique bulletin of the international association of medicine. J Tech Methods 1929;12:75.

23. Verhoeff FH. Some new staining methods of wide applicability. Including a rapid differential stain for elastic tissue. JAMA 1908; 50:876.

24. Ofem O, Ani E, Okoi O, Effiang A, Eno A, Ibu J. Effect of Viscum album (mistletoe) extract on some serum electrolytes, organ weight and cytoarchitecture of the heart, kidney and blood vessels in high salt-fed rats. The Internet Journal Nutrition and Wellness 2006; 4.

25. Adewole SO, Adenowo T, Naicker T, Ojewole JA. Hypoglycaemic and hypotensive effect of Ficus exasperata vahl. (Moraceae) leaf aqueous extract in rats. Afr $\mathrm{J}$ Tradit Complement Altern Med 2011;8:275-83.

26. Du Cailar G, Ribstein J, Daures JP, Mimran A. Sodium and left ventricular mass in untreated hypertensive and normotensive subjects. Am J Physiol 1992;263:H177-81.

27. Komolafe OA, Ofusori DA, Adewole OS, Ayoka AO, Bejide R. Histological and histochemical studies of the aorta and pulmonary trunk in STZ-induced diabetic Wistar rats treated with Momordica charantia. International Journal of Morphology 2013; 31:716-23.

28. Van Bortel LM, Struijker-Boudier HA, Safar ME. Pulse pressure, arterial stiffness and drug treatment of hypertension. Hypertension 2001;38:914-21. 
29. Banerjee SK, Mukherjee PK, Maulik SK. Garlic as an antioxidant: the good, the bad and the ugly. Phytother Res 2003;17:97-106.

30. Sharifi AM, Darabi R, Akbarbo N. Investigation of antihypertensive mechanism of garlic in 2KIC hypertensive rat. J Ethnopharmacol 2003;86:219-24.

31. Irani K. Angiotensin II-stimulated vascular remodeling. Circ Res 2001;88:858-60.
32. Varagic J, Frohlich ED, Susic D, Ahn J, Matavelli L, López B. AT1 receptor antagonism attenuates target organ effects of salt excess in SHRs without affecting pressure. Am J Physiol Heart Circ Physiol 2008;294:853-8.

33. Palmer BF. Managing hyperkalemia caused by inhibitors of the rennin-angiotensin aldosterone system. N Engl J Med 2004;351: 585- 92 .

Correspondence to: Olusola Stephen Saka, MSc

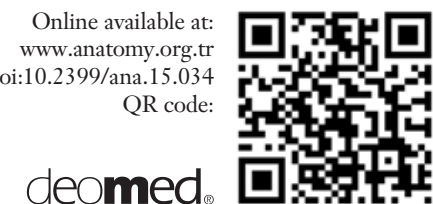
Faculty of Basic Medical Sciences, Obafemi Awolowo University, Ile-Ife, Osun-State, Nigeria

Phone: +234806 7646211 e-mail: olusolasaka1@gmail.com

Conflict of interest statement: No conflicts declared.

This is an open access article distributed under the terms of the Creative Commons Attribution-NonCommercial-NoDerivs 3.0 Unported (CC BY-NCND3.0) Licence (http://creativecommons.org/licenses/by-nc-nd/3.0/) which permits unrestricted noncommercial use, distribution, and reproduction in any medium, provided the original work is properly cited. Please cite this article as: Saka OS, Komolafe AO, Ogunlade O, Olayode AA, Akinjisola AA. Aqueous extract of garlic (Allium sativum) administration alleviates high salt diet-induced changes in the aorta of adult Wistar rats: a morphological and morphometric study. Anatomy 2016;10(1):8-15. 